Check for updates

Cite this: RSC Adv., 2018, 8, 18284

\title{
Removal of tetracycline by aerobic granular sludge and its bacterial community dynamics in SBR
}

\author{
Xiaochun Wang, ${ }^{a}$ Zhonglin Chen, ${ }^{a}$ Jing Kang, (D) *a Xia Zhao ${ }^{\mathrm{b}}$ and Jimin Shen ${ }^{* a}$
}

In this study, the removal efficiency and mechanism of tetracycline by aerobic granular sludge (AGS) in SBR were investigated. The removal of tetracycline present in livestock and poultry wastewater and the effect on conventional pollutants, such chemical oxygen demand, and nitrogen and phosphorous removal performance have been assessed demonstrating that AGS was able to remove tetracycline by adsorption and biodegradation processes. The removal rate of tetracycline was more than $90 \%$, and conventional pollutants were also efficiently removed. The high-throughput sequencing technology was applied to decipher the species succession and community structure of tetracycline-resistance granular sludge. The Chryseobacterium, Actinotignum, Lactococcus, Shinella and Clavibacter were gradually dominant and considered as the functional bacteria for the removal of tetracycline. The numbers of functional genes including amino acid, carbohydrate and inorganic ion transport and metabolism, as well as energy production and conversion, and secondary metabolites biosynthesis, were also increased. These functional genes played an important role in the biodegradation of tetracycline.

Received 12th February 2018 Accepted 4th May 2018

DOI: $10.1039 / \mathrm{c} 8 \mathrm{ra01357h}$

rsc.li/rsc-advances through feces, urine, and wastewater from cleaning the coop, which produce several pollutants, including nitrogen, phosphorus, and antibiotics. ${ }^{12}$ The US and EU countries have conducted investigations and research on antibiotic residues in the environment and made risk assessments. ${ }^{13-15}$

The removal methods of antibiotics mainly include biological treatment, chemical oxidation, photocatalytic oxidation, and membrane technology, the removal rates of antibiotics were more than $80 \%, 85 \%, 90 \%$ and $90 \%$, respectively. ${ }^{\mathbf{1 4}-18}$ The membrane technology merely transform antibiotics from one state to another, and the antibiotics may return to the environment and cause potential damage. This study proposes to treat wastewater from livestock and poultry using the AGS technology for remove of antibiotics. As a biological treatment method of great potential, the AGS technology has a number of advantages with high biomass, strong impact resistance load, long SRT, high removal efficiency for pollutant, and it can reduce construction investment and operation costs.

In this paper, the antibiotic drug, tetracycline was selected as the target organic pollutant, which is frequently detected in the wastewater from livestock and poultry. The removal efficiency of tetracycline by granular sludge in aerobic granular sludge sequencing batch reactor (AGSBR) was studied. A labscale AGSBR was introduced to explore the performance, formation and microbial succession of granular sludge for effectively removing tetracycline. The high-throughput sequencing detection is used to clarify the cometabolism of microbial community in the AGSBR system.
${ }^{a}$ State Key Laboratory of Urban Water Resource and Environment, School of Environment, Harbin Institute of Technology, Harbin 150090, China. E-mail: jingkanghit@163.com; shenjimin@hit.edu.cn; Fax: +86-451-86283028; Tel: +86-45186283001; +86-451-86287000

${ }^{b}$ College of Petrochemical Technology, Lanzhou University of Technology, Lanzhou 730050, China 
Table 1 Concentrations of antibiotics in real wastewaters

\begin{tabular}{|c|c|c|c|c|}
\hline Class & Compound & Sample & Concentration $\left(\mu \mathrm{g} \mathrm{L}^{-1}\right)$ & Reference \\
\hline Tetracyclines & Tetracycline & $\begin{array}{l}\text { Treatment plant wastewater } \\
\text { and swine wastewater }\end{array}$ & $30.5-388.70$ & 6 and 7 \\
\hline & Chlortetracycline & plant wastewater & $3.08-32.67$ & 6 and 9 \\
\hline & Sulfamethoxazole & & $14.05-316.50$ & 9 and 10 \\
\hline Sulfonamides & Sulfamonomethoxine & Swine wastewater & 45.40 & 11 \\
\hline & Ciprofloxacin & & $0.02-0.17$ & 6 \\
\hline
\end{tabular}

\section{Materials and methods}

\section{Wastewater composition and experimental granular sludge}

Synthetic wastewater was prepared to simulate containing tetracycline wastewater. The actual livestock and poultry wastewater was obtained from a swine farm in Harbin, China. The concentrations of COD, ammonia nitrogen $\left(\mathrm{NH}_{4}{ }^{+}-\mathrm{N}\right)$, TP and tetracycline in the swine wastewater were $3000 \mathrm{mg} \mathrm{L}^{-1}$, $214 \mathrm{mg} \mathrm{L} \mathrm{L}^{-1}, 27.5 \mathrm{mg} \mathrm{L}^{-1}$, and $265 \mu \mathrm{g} \mathrm{\textrm {L } ^ { - 1 }}$ respectively. According to the adaptability of granular sludge growth, with reference to the actual value of pollutants in the wastewater, ${ }^{19,20}$ the concentrations of $\mathrm{COD}, \mathrm{NH}_{4}{ }^{+}-\mathrm{N}$, TP and tetracycline in simulated experimental wastewater were approximately $3000 \pm 200 \mathrm{mg} \mathrm{L}{ }^{-1}, 150 \pm 20 \mathrm{mg} \mathrm{L}^{-1}, 26 \pm$ $2 \mathrm{mg} \mathrm{L}^{-1}$, and $300 \pm 10 \mu \mathrm{g} \mathrm{L}^{-1}$ respectively. The synthetic wastewater was composed of: $2104 \mathrm{mg} \mathrm{L}^{-1} \mathrm{C}_{6} \mathrm{H}_{12} \mathrm{O}_{6}$, $1403 \mathrm{mg} \mathrm{L}^{-1} \mathrm{CH}_{3} \mathrm{COONa}, 551 \mathrm{mg} \mathrm{L}^{-1} \mathrm{NH}_{4} \mathrm{Cl}, 78.4 \mathrm{mg} \mathrm{L}^{-1}$ $\mathrm{KH}_{2} \mathrm{PO}_{4}$, and $\mathrm{K}_{2} \mathrm{HPO}_{4} \cdot 3 \mathrm{H}_{2} \mathrm{O}$.

Experimental sludge was well-trained AGS in the SBR. The SBR was operated for about 60 days. The system was controlled by a programmable logic controller (PLC). The volumetric exchange ratio (VER) was $50 \%$ for each cycle. Every operated cycle of the reactor took $2.4 \mathrm{~h}$. Generally each cycle included 10 min of feeding, 110-128 min of aerobic phase, 2-20 min of settling time and $4 \mathrm{~min}$ of effluent discharge phase. The aeration rate was $0.2 \mathrm{~m}^{3} \mathrm{~h}^{-1}$, and the AGS of experimental used was obtained after 60 days of operation. The particle size of AGS was approximately 2-3 $\mathrm{mm}$ with compact structure and smooth surface. Microscopic examination of the obtained AGS revealed a large number of filamentous bacteria and a small number of protozoa, mainly consisting of Vorticella.

\section{Experimental equipment and operational condition}

The height/diameter ratio $(H / D)$ of the SBR reactor was 15 , its working volume was $625 \mathrm{~mL}$, and the VER was 50\%. The reactor was operated under the optimized conditions. The system operated 6 cycles daily, and each cycle of the reactor took $4 \mathrm{~h}$. The aeration rate was $0.3 \mathrm{~m}^{3} \mathrm{~h}^{-1}$ that displayed using a gas flow meter. The system was controlled by the PLC. The reaction apparatus was set up as two parallel reactors, the blank reactor (R1) and the target reactor (R2), which were reactors in the absence and presence of tetracycline, respectively.

\section{Chemical analysis}

The tetracycline was analyzed using Agilent 6890 series HPLC with ultraviolet detector. The column used was an Agilent Eclipse XDB-C18 chromatography column $(4.6 \mathrm{~mm} \times 250 \mathrm{~mm}$, $5 \mu \mathrm{m})$. The moving phase ratio was $0.1 \%$ acetic acid: acetonitrile $=80 \%: 20 \%$. The flow rate was $1 \mathrm{~mL} \mathrm{~min}^{-1}$, and the detection wavelength was $359 \mathrm{~nm}$. The morphology of granular sludge was observed by a digital camera, and microscopic morphology was observed by scanning electron microscopy (SEM; FEI Sirion SEM). The wastewater parameters of COD, $\mathrm{NH}_{4}{ }^{+}-\mathrm{N}$, TP, and mixed liquor suspended solids (MLSS) were analyzed according to the Standard Methods. ${ }^{21}$ The adsorption amount of the AGS on tetracycline was calculated by performing a mass balance using the following equation:

$$
q_{t}=\frac{C_{0}-C_{t}}{\mathrm{MLSS}}
$$

where $q_{t}$ is the amount of adsorbed tetracycline at time $t$ (mg $\left.\mathrm{g}^{-1}\right) ; C_{0}\left(\mathrm{mg} \mathrm{L}^{-1}\right)$ and $C_{t}\left(\mathrm{mg} \mathrm{L}^{-1}\right)$ are the initial and residual tetracycline concentrations, respectively. ${ }^{22}$ The biodegradation amount of the AGS on tetracycline was calculated using the following formula:

$$
C_{\mathrm{d}}=C_{0}-C_{\mathrm{e}}-q_{t} \mathrm{MLSS}
$$

where $C_{\mathrm{d}}$ is the amount of degradation tetracycline $\left(\mathrm{mg} \mathrm{g}^{-1}\right) ; C_{\mathrm{e}}$ $\left(\mathrm{mg} \mathrm{L}^{-1}\right)$ is the effluent concentration of tetracycline.

\section{Adsorption and degradation experiments of tetracycline}

The photodegradation and adsorption of containers on tetracycline could be neglected in the absence of granules. ${ }^{22}$ The AGS was sterilized and used for adsorption experiment and the inactivation of granules was carried out with the addition of sodium azide $\left(\mathrm{NaN}_{3}\right)$ at $0.3 \%$ weight to volume $(\mathrm{w} / \mathrm{v}) \cdot{ }^{22,23}$ Before experiment, the granular sludge sample was rinsed three times with deionized water. The adsorption kinetic experiments of the AGS on tetracycline were conducted in $100 \mathrm{~mL}$ glass beakers with tetracycline solution at various concentration (1, 2, 5, 10, and $15 \mathrm{mg} \mathrm{L}^{-1}$ ). The granular sludge mass of $10 \mathrm{~g}$ was used at the beginning of the tests. Under the condition of continuous oscillating with a constant temperature water bath oscillator, samples were collected at predetermined time intervals. The concentrations of residual tetracycline were 
measured immediately after it was filtered with a $0.22 \mu \mathrm{m}$ filter membrane. The total removal kinetic experiments were done in the similar way used for the adsorption kinetics experiments except for the presence of sludge activities. The amount of degradation in the degradation kinetics experiment was the total removal amount of the AGS on tetracycline deducted the adsorption amount.

\section{DNA extraction}

Sludge samples $(10 \mathrm{~mL})$ were collected from $\mathrm{R} 1$ and $\mathrm{R} 2$ reactors operating at 1 (R1-1 and R2-1), 15 (R1-2 and R2-2), 30 (R1-3 and R2-3), 45 (R1-4 and R2-4), 60 (R1-5 and R2-5), and 75 days (R1-6 and R2-6), respectively. The collected samples were then pretreated before genomic DNA extraction to ensure the collection of sufficient genomes from the samples and to remove humus and other impurities. The DNA extraction was performed using OMEGA E.Z.N.A ${ }^{\mathrm{TM}}$ Mag-Bind Soil DNA Kit. The concentration and quality of the extracted DNA were determined using electrophoresis on a $1 \%$ (weight/volume) agarose gel. Then extracted DNA was stored at $-20{ }^{\circ} \mathrm{C}$ until analysis.

\section{PCR amplification and high-throughput sequencing}

The DNA was amplified with a set of primers targeting of the bacteria (16S rDNA), and two rounds of amplification were performed. The first round of amplification was quantitated by Qubit 2.0 DNA assay kit to determine the amount of DNA that should be added for the PCR reaction. Universal primers: $341 \mathrm{~F}$ primers: CCCTACACGACGCTCTTCCGATCTG (barcode) CCTACGGGNGGCWGCAG; 805R primers: GACTGGAGTTCCTTGGCACCCGAGAATTCCAGACTACHVGTATCTAATCC. The system is carried out as follows: $2 \times$ Taq master Mix $(15 \mu \mathrm{L})$, Bar-PCR primer $\mathrm{F}(10 \mu \mathrm{M})(1 \mu \mathrm{L})$, primer $\mathrm{R}(10 \mu \mathrm{M})(1 \mu \mathrm{L})$, genomic DNA (10-20 ng), added $\mathrm{H}_{2} \mathrm{O}$ to $30 \mu \mathrm{L}$. Amplifications were run under the following cycling conditions: $1 \times 94{ }^{\circ} \mathrm{C}$ $3 \mathrm{~min} ; 5 \times\left(94{ }^{\circ} \mathrm{C} 30 \mathrm{~s}, 45{ }^{\circ} \mathrm{C} 20 \mathrm{~s}, 65{ }^{\circ} \mathrm{C} 30 \mathrm{~s}\right) ; 20 \times\left(94{ }^{\circ} \mathrm{C} 20 \mathrm{~s}\right.$, $\left.55{ }^{\circ} \mathrm{C} 20 \mathrm{~s}, 72{ }^{\circ} \mathrm{C} 30 \mathrm{~s}\right) ; 1 \times 72{ }^{\circ} \mathrm{C} 5 \mathrm{~min}$; with a final soak at $10^{\circ} \mathrm{C}$. Illumina Bridge PCR-compatible primers were introduced for the second round of PCR. The PCR system was performed as follows: $2 \times$ Taq master Mix $(15 \mu \mathrm{L})$, primer $\mathrm{F}(10 \mu \mathrm{M})(1 \mu \mathrm{L})$, primer $\mathrm{R}(10 \mu \mathrm{M})(1 \mu \mathrm{L})$, genomic DNA (20 ng), finally add $\mathrm{H}_{2} \mathrm{O}$ to $30 \mu \mathrm{L}$. Amplifications were run under the following cycling conditions: $1 \times 95{ }^{\circ} \mathrm{C} 30 \mathrm{~s} ; 5 \times\left(95^{\circ} \mathrm{C} 15 \mathrm{~s}, 55^{\circ} \mathrm{C} 15 \mathrm{~s}, 72{ }^{\circ} \mathrm{C} 30 \mathrm{~s}\right)$; $1 \times 72{ }^{\circ} \mathrm{C} 5 \mathrm{~min}$; with a final soak at $10{ }^{\circ} \mathrm{C}$. The raw sequence data were cleaned, reduced and analysed using Mothur Version 1.36.1. ${ }^{24}$ The chimeras were eliminated using the implanted code UCHIME. ${ }^{25}$ The reference and taxonomy files were adopted from the Greengenes database. ${ }^{24}$ COG-based methodology was drawn from $g$ plots package using R software.
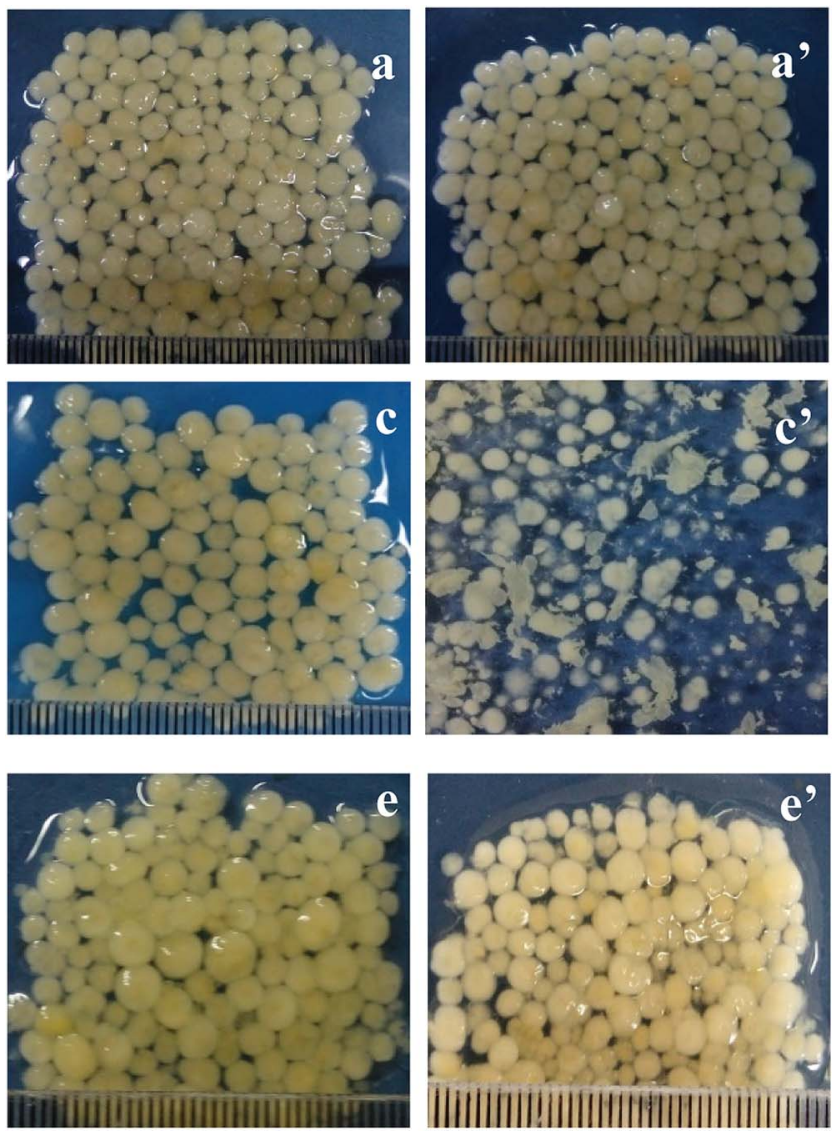
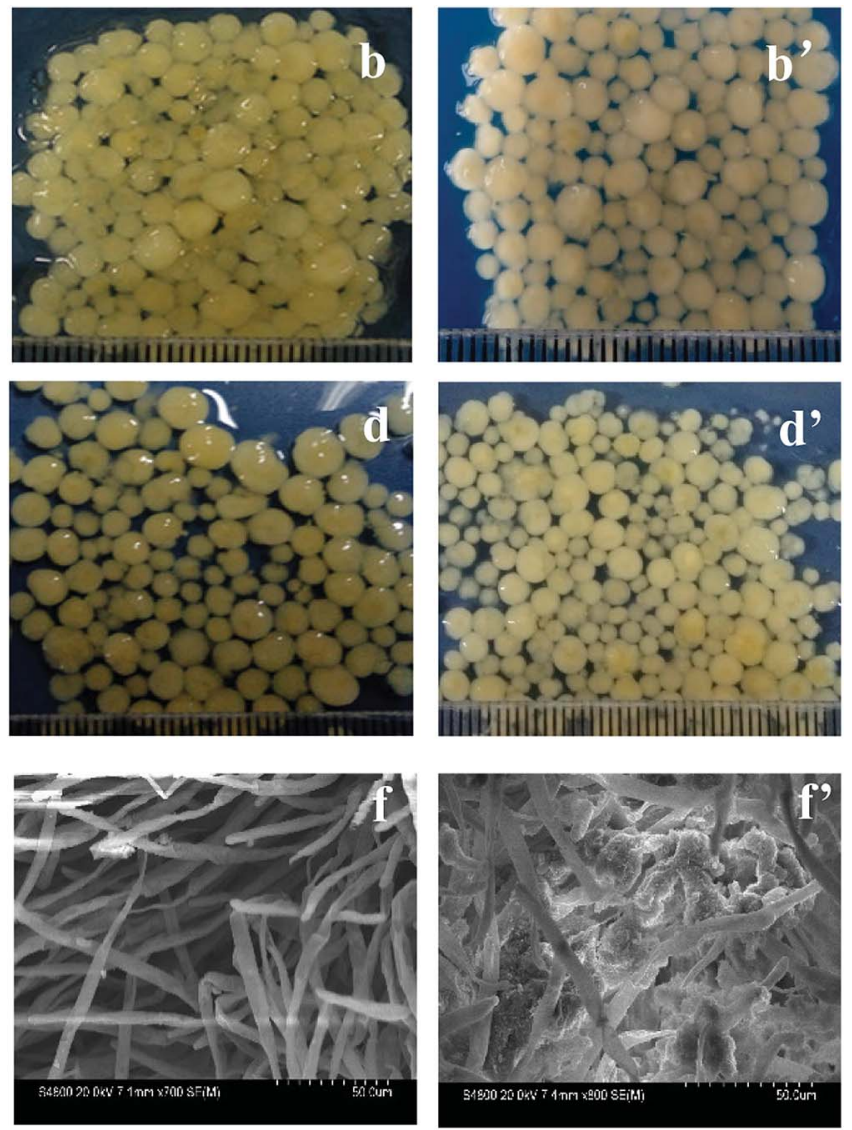

Fig. 1 Photographs and micrographs of aerobic granular sludge in two reactors during different phases. (a) and (a') Inoculated sludge, (b) and ( $\left.b^{\prime}\right)$ day 12 in R1 and R2, (c) and ( $c^{\prime}$ ) day 22 in R1 and R2, (d) and (d') day 46 in R1 and R2, (e) and (e') day 65 in R1 and R2, (f) and (f') SEM of aerobic granules in $\mathrm{R} 1$ and $\mathrm{R} 2$ at 65 days: $(\mathrm{f}) \times 700,\left(f^{\prime}\right) \times 800$, respectively. 


\section{Results and discussion}

\section{Morphological characteristics of granular sludge}

The morphologies of AGS in SBR during different periods are shown in Fig. 1. The particle diameters of inoculated sludges in the $\mathrm{R} 1$ and $\mathrm{R} 2$ reactors are around $2 \mathrm{~mm}$ to $3 \mathrm{~mm}$ with a smooth surface (Fig. 1a and $\mathrm{a}^{\prime}$ ). As the operation time increased, the surface of AGS in R2 is not smooth and has turned into pale pink, which due to the drug tetracycline, as shown in Fig. 1b'. However, particle sizes of granular sludges increased slightly. From 22 days of operation, the morphology of the granular sludge changed significantly. Some sludge particles were villous granules, and their particle sizes decreased. Other granular sludge has become thin flakes with irregular margins (Fig. $1 \mathrm{c}^{\prime}$ ). It can be clearly seen from Fig. $1 c^{\prime}$ that the addition of tetracycline had a significant influence on microbial communities. ${ }^{26}$ Afterward, the particles grow rapidly, such that the size evidently increased on the 46 days of operation. The particles are smooth and sphere-shaped, and appeared as compact granules, indicating that the granular sludge had become acclimated to the tetracycline (Fig. 1d'). Because of the effect of tetracycline on microbes, the morphology of AGS changed during the operation. With the increase of operation time, microbes gradually adapted to the environment, which made AGS maintain good morphology in $\mathrm{R} 2$ reactor with the addition of tetracycline. Fig. 1e and $\mathrm{e}^{\prime}$ showed the morphologies of granular sludge in the $\mathrm{R} 1$ and $\mathrm{R} 2$ reactors at 65 days of operation, respectively. The particle sizes of granular sludge were around 3 to $4 \mathrm{~mm}$ with smooth and glossy surface, and both were bright. However, the colors of granular sludges were light yellow and light pink for the R1 and R2 reactors, respectively. The difference of colors is due to the diversity of microorganism species and quantity.

Fig. If and $\mathrm{f}^{\prime}$ showed the SEM morphologies of the granular sludges in R1 and R2 at 65 days of operation, respectively. Fig. 1f showed the granular sludge in R1 was mainly composed of filamentous fungi, while Fig. $1 \mathrm{f}^{\prime}$ showed that the other microorganisms attached to the skeleton structure were formed by filamentous fungi. ${ }^{27}$ Filamentous fungi identified and the accession number of the sequence was MH156038.

\section{Analysis of sludge biomass and settling ability}

The changes of MLSS and sludge volume index (SVI) value throughout the experiment are shown in Fig. 2. The MLSS concentration of inoculated sludge was $10.06 \mathrm{~g} \mathrm{~L}^{-1}$. Most of the biomass was washed out at the beginning of reactor operation. Thus the MLSS concentrations of R1 and R2 subsequently decreased to $6.0 \mathrm{~g} \mathrm{~L}^{-1}$ and $4.0 \mathrm{~g} \mathrm{~L}^{-1}$ at 30 days of operation, respectively. With the operation time increased, the MLSS concentration steadily increased, presumably because the microbial community gradually adapted to the added tetracycline. In the late stage, the MLSS concentrations of R1 and R2 reached to $9.0 \mathrm{~g} \mathrm{~L}^{-1}$ and $6.0 \mathrm{~g} \mathrm{~L}^{-1}$, respectively. The SVI of inoculated sludge was $54.67 \mathrm{~mL} \mathrm{~g}^{-1}$, the SVI of granular sludge decreased with increasing operation time, and the SVI in R1 and $\mathrm{R} 2$ reactors decreased to $51.78 \mathrm{~mL} \mathrm{~g}^{-1}$ and $54.09 \mathrm{~mL} \mathrm{~g}^{-1}$ in the

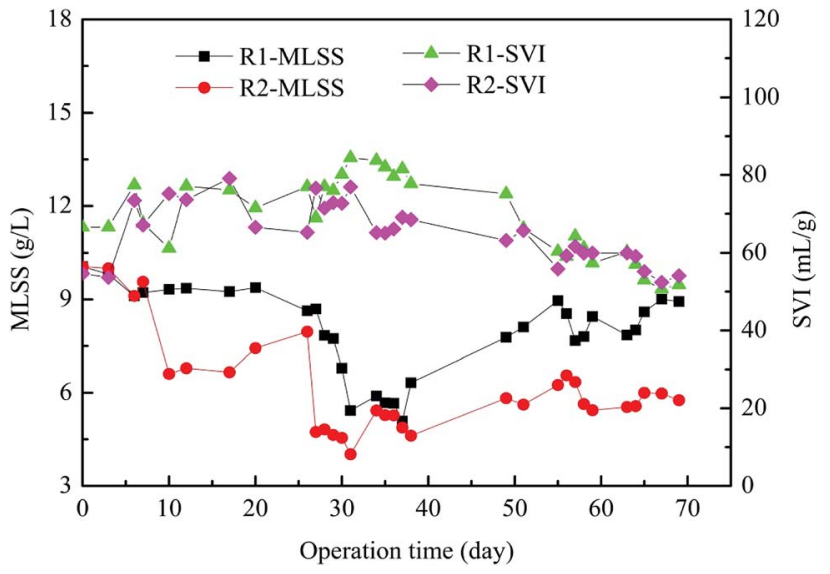

Fig. 2 The biomass and sedimentation performance of granular sludge in AGSBR. The standard deviations of the values were within $5 \%$ $(n=3)$.

late period, respectively. It is because the biomass of granular sludge decreased, which had a certain influence on SVI. Experimental results showed that tetracycline affected both the MLSS and SVI of AGS.

\section{Effect of tetracycline on AGSBR performance}

The removal of conventional pollutants, such as COD, $\mathrm{NH}_{4}{ }^{+}-\mathrm{N}$ and TP through the AGSBR technology during different operation phases were studied, and the results are shown in Fig. 3. Fig. 3a presents the removal performances of AGS on COD in R1 and $\mathrm{R} 2$ reactors over 75 days. The removal rate of COD presented a steady trend with increasing operation time, and it was maintained at $98 \%$ in both reactors during the late stage. The average effluent concentrations of COD in R1 and R2 throughout the whole operation were $40.06 \mathrm{mg} \mathrm{L}^{-1}$ and $44.98 \mathrm{mg} \mathrm{L}^{-1}$, respectively.

The removal effect of the AGS on $\mathrm{NH}_{4}{ }^{+}-\mathrm{N}$ is shown in Fig. $3 \mathrm{~b}$. In the beginning of operation, the removal rates of $\mathrm{NH}_{4}{ }^{+} \mathrm{N}$ in R1 and $\mathrm{R} 2$ were $81.33 \%$ and $80.20 \%$, respectively. The removal rates first decreased and then increased with increasing operation time, and they increased to $87 \%$ and $88 \%$ in R1 and R2 respectively, as the operation time increased to 75 days. The average effluent concentrations of $\mathrm{NH}_{4}{ }^{+}-\mathrm{N}$ in $\mathrm{R} 1$ and $\mathrm{R} 2$ throughout the whole operation were $19.34 \mathrm{mg} \mathrm{L}^{-1}$ and $19.86 \mathrm{mg} \mathrm{L}^{-1}$, respectively.

As shown in Fig. 3c, the removal rate of TP has a fluctuation in the early operation. With increasing operation time, the removal rate of TP in R1 decreased from $89.42 \%$ to $83.51 \%$, whereas that in $\mathrm{R} 2$ increased from $87.31 \%$ to $81.47 \%$, and then removal rates of TP in both reactors increased. The removal rates of TP in R1 and $\mathrm{R} 2$ were maintained at above $94.00 \%$ and $98.00 \%$ respectively, indicating that the addition of tetracycline improved TP removal performance, and the metabolic activity of polyphosphate accumulating bacteria in R2 might be promoted. The average effluent concentrations of TP in R1 and R2 throughout the whole operation were $1.76 \mathrm{mg} \mathrm{L}^{-1}$ and $1.64 \mathrm{mg} \mathrm{L}^{-1}$, respectively. The results of experiment showed that granular sludge had a good removal effect on tetracycline-containing wastewater. 


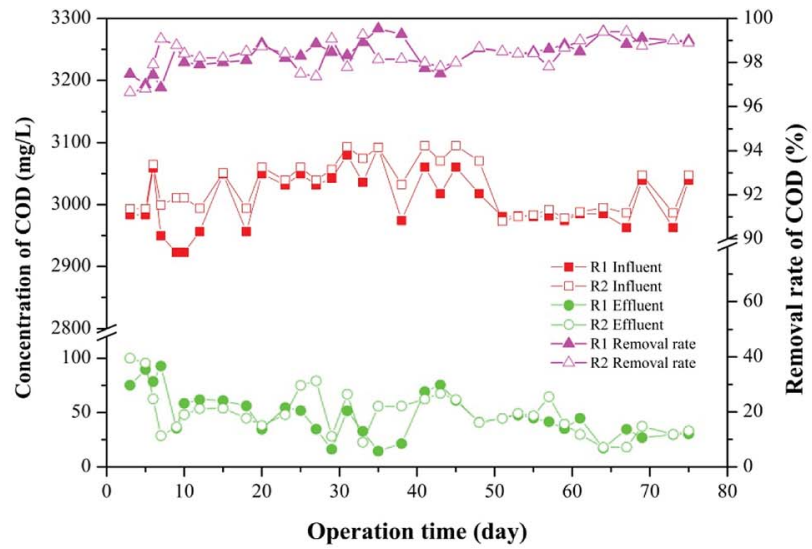

(a)

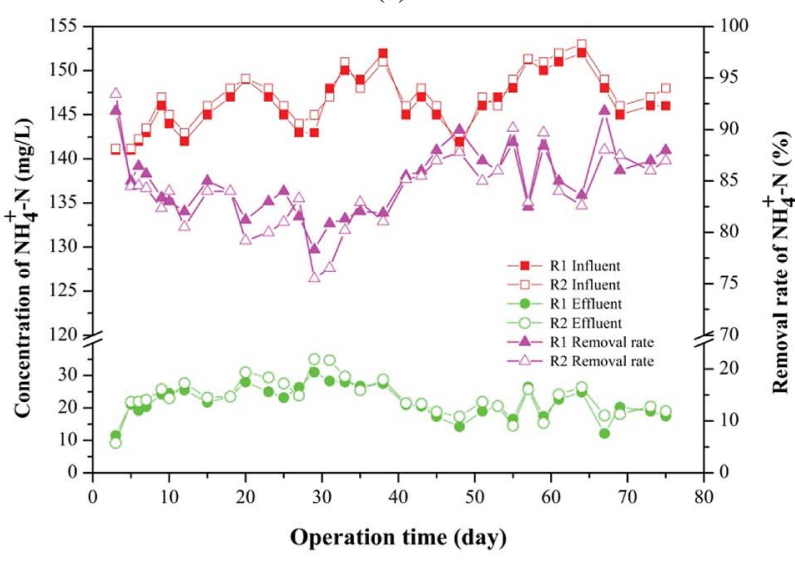

(b)

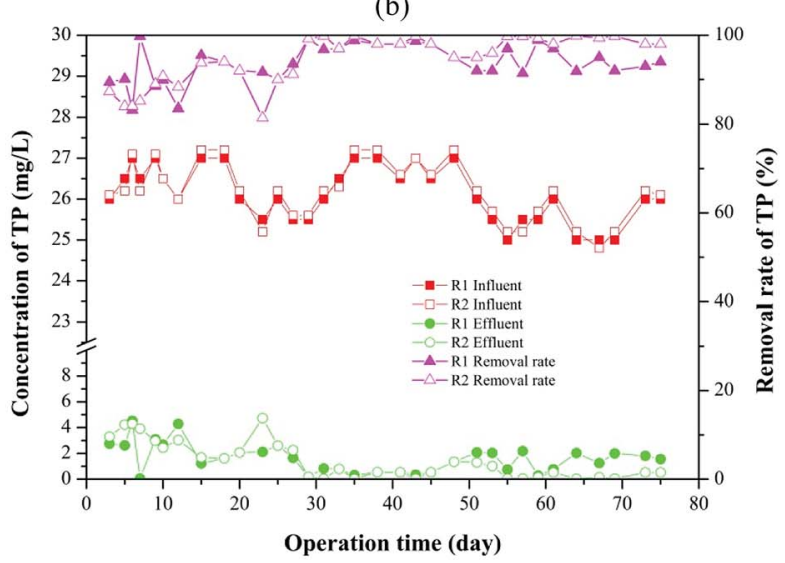

(c)

Fig. 3 Removal of conventional pollutants in AGSBR during different operation phases. (a) COD, (b) $\mathrm{NH}_{4}^{+}-\mathrm{N}$, (c) TP.

\section{Removal of tetracycline}

The removal effect of the AGS on tetracycline is shown in Fig. 4. It can be seen that the removal rate is low at $74 \%$ during the initial stage of adding tetracycline in the $\mathrm{R} 2$ reactor. The removal effect has no obvious improvement after several days of operation. The AGS had very little degradation effect for tetracycline in a short period but mainly relied on its adsorption. ${ }^{28,29}$ After 30 days of operation, the effluent concentration of tetracycline decreased, and the removal rate increased to $81 \%$. This

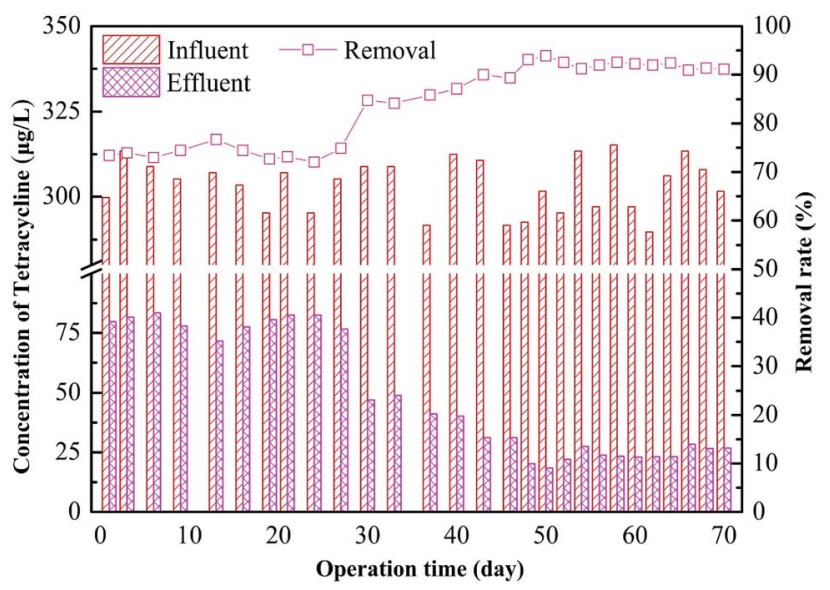

Fig. 4 Removal of tetracycline in the R2 reactor during different operation phases.

is probably because at the initial stage, removal of tetracycline mainly depended on the adsorption of the drug to the outer surface of the sludge granules. The tetracycline is organic molecule, its molecular sieve effect lead to a slow adsorption process inside the particles. ${ }^{30}$ The microbes gradually adapted to the tetracycline in the system with time, and the removal of all tetracycline tested here improved. Subsequently, the removal of tetracycline by the AGSBR technology tended to be stable with the removal rate maintaining at $90 \%$, and the effluent concentration of tetracycline was about $25 \mu \mathrm{g} \mathrm{\textrm {L } ^ { - 1 }}$.

\section{Adsorption and biodegradation of granular sludge on tetracycline}

Fig. 5 showed the adsorption and biodegradation of the AGS on tetracycline in the concentration range of $1-15 \mathrm{mg} \mathrm{L}^{-1}$. It can be clearly seen from Fig. 5a that the adsorption amount of the AGS on tetracycline increased with the increasing tetracycline concentration. When the adsorption time was exceeded than $30 \mathrm{~h}$, the amount of adsorption was essentially unchanged. When the tetracycline concentration was $15 \mathrm{mg} \mathrm{L}^{-1}$, the maximum adsorption could reach $1.21 \mathrm{mg} \mathrm{g}^{-1}$. The adsorption capacity of the AGS on tetracycline was lower than nonbiological materials. ${ }^{31}$ Fig. $5 \mathrm{~b}$ showed the biodegradation of the AGS on tetracycline. The degradation amount of the AGS on tetracycline also increased with the increasing tetracycline concentration, and the amount of degradation was greater than the adsorption in the entire reaction. When the reaction time was exceeded than $12 \mathrm{~h}$, the amount of degradation is essentially unchanged.

The total removal amount of the AGS on tetracycline was shown in Fig. 5c. When the reaction time was exceeded than $12 \mathrm{~h}$, the total removal amount of tetracycline tended to be stable, which was similar to the trend of degradation. It can be evidenced that the degradation of the AGS on tetracycline was greater than adsorption. The proportions of adsorption and degradation in total removal amount of tetracycline was shown in Fig. 5d. With the increasing tetracycline concentration, the proportion of degradation increased, whereas the proportion of 


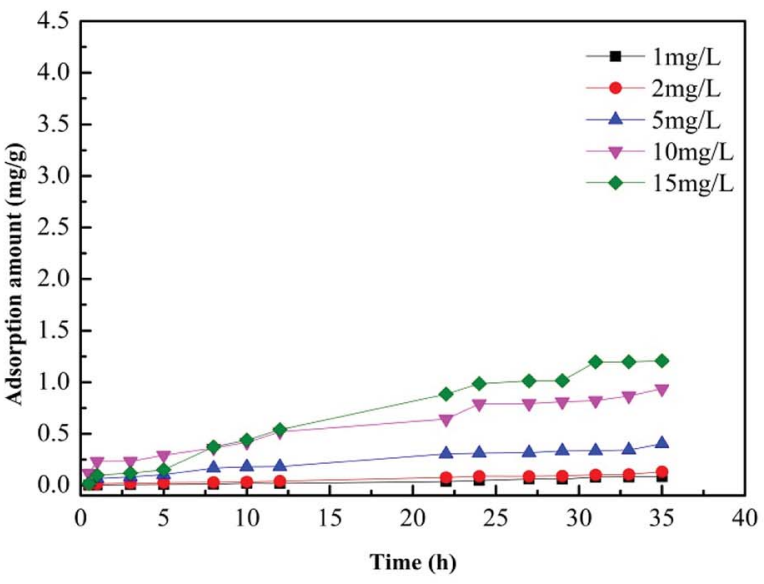

(a)

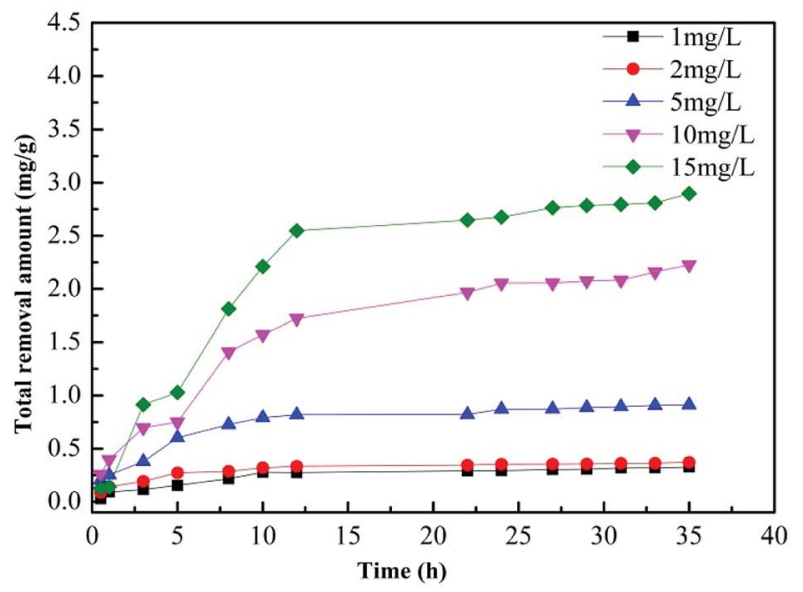

(c)

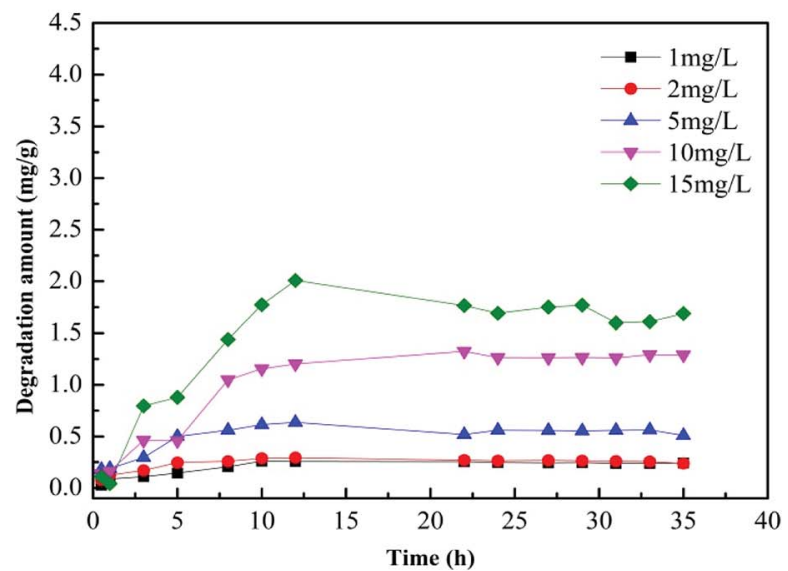

(b)

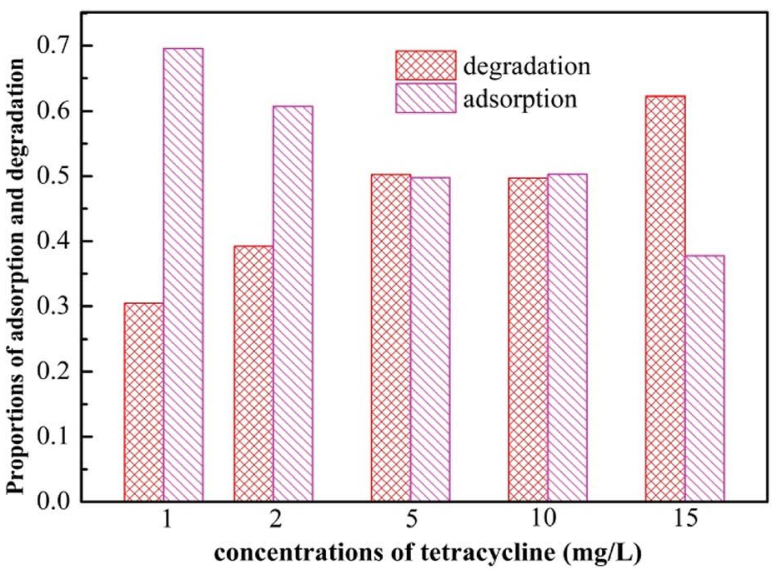

(d)

Fig. 5 Adsorption and degradation of the granular sludge on tetracycline at different initial concentrations: (a) adsorption, (b) degradation, (c) total removal; (d) proportions of adsorption and degradation.

adsorption was gradually reduced. When the tetracycline concentration was $15 \mathrm{mg} \mathrm{L}^{-1}$, the proportion of biodegradation reached $62 \%$. Experiments proved that AGS removed tetracycline by adsorption and biodegradation, and its biodegradation played a dominant role.

\section{The enrichment and succession of microbial community in AGSBR}

The microbial community of the AGS in AGSBR was analyzed by high-throughput pyrosequencing to evaluate whether there were significant shifts in the composition of the microbial communities throughout bioreactor operation. Fig. 6 showed the dynamic variation of microbial genus classification levels among the different operating times. The microbial community structures at added tetracycline were quite different at genus level, moreover, some genera showed an increasing or decreasing tendency with added tetracycline. The Chryseobacterium exhibited a special phenomenon in the operation phase. After the addition of tetracycline drugs, the relative abundance increased form $5.61 \%$ to $15.5 \%$ in sample $\mathrm{R} 2-2$.
Subsequently, it gradually decreased to $4.92 \%$ in sample R2-6. The abundance of Chryseobacterium was 3.7\% in sample R1-6. The Chryseobacterium is highly resistant to several antimicrobial drugs, such as the third generation cephalosporins, aminoglycoside, carbapenemases and tetracycline. ${ }^{32-34}$ Its drugresistance mechanism is due to the production of $\beta$-lactamase induced by chromosomes, except outside the permeable barrier of the bacterial membrane. The Actinotignum was enriched in $\mathrm{R} 1$ reactor with the relative abundance increasing from $0.73 \%$ to $19.97 \%$, which was probably because the Actinotignum adapted to the operational conditions of the AGSBR technology with time. The enrichment phenomenon was improved in R2 reactor with the relative abundance increasing from $2.02 \%$ to $25.91 \%$. The Actinotignum became the most dominant genus of AGS in R1-6 and R2-6. The study showed that the bacterial genus could take tetracycline as the carbon source, ${ }^{32-34}$ which was helpful for removing tetracycline. The Actinotignum is more common than implied by routine cultivation. ${ }^{35,36}$ It is easy to adapt to the environment, so the Actinotignum gradually increased both in R1 and R2. The Lactococcus and Shinella were also similar enriched in both reactors and also make important 


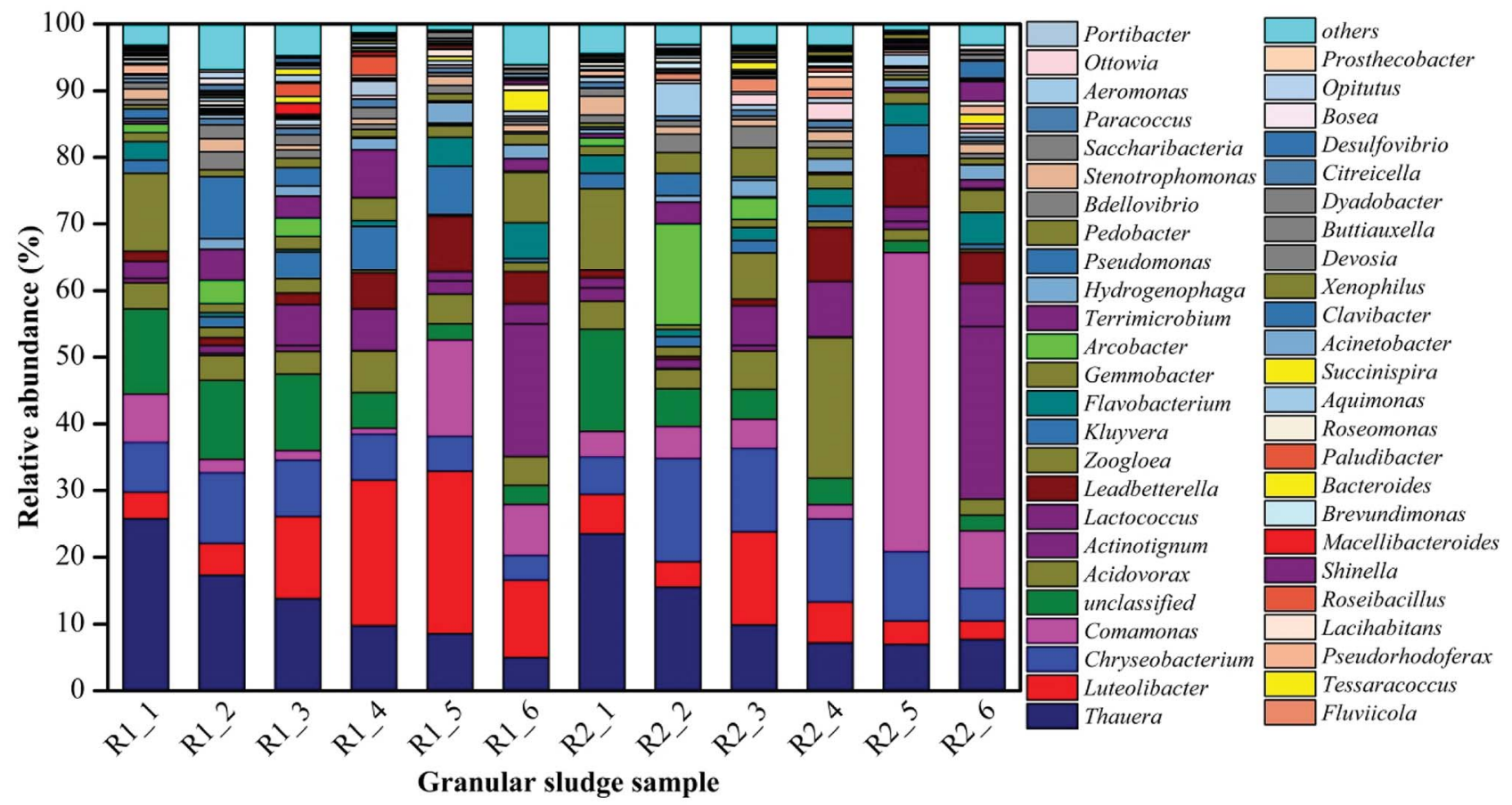

Fig. 6 Analysis of microbial diversity at genus level for different samples from two reactors.

contributions toward tetracycline removal. In addition, the Clavibacter was not detected in R1 reactor, while with the addition of tetracycline, the abundance of Clavibacter increased to $2.58 \%$ in R2-6. This increasing dynamic change indicated that the Clavibacter was capable to adapt the tetracycline drugs and contributed to granular sludge for the removal of tetracycline.

It can be seen from Fig. 6 that some strains exhibited the enrichment phenomenon in the process of added tetracycline. For example, the Comamonas appeared the increasing trend in R2 reactor contrast to R1 with the increase of operation time, and dominated in AGS, which was the relative abundance increased from $3.81 \%$ to $44.92 \%$ in R2-5. But with the operation time, the abundance of the Comamonas dropped to $8.55 \%$ in R2-6. The Comamonas was always existed in all sludge samples during the whole process, indicating that the Comamonas could contributed to granular sludge for the resistance of tetracycline. The literature has reported the Comamonas has strong degradation ability to naphthalene, catechol, phenol, A-naphthol, salicylic acid, and phthalic acid, ${ }^{37}$ the molecular structure of tetracycline is similar to those of above compounds, thus its degradation of tetracycline is associated with large-subunit naphthalene-dioxygenase ironsulfur protein genes and small-subunit naphthalenedioxygenase iron-sulfur protein genes in the bacterial genus. The Flavobacterium and Leadbetterella have been suggested as functional syntrophic naphthalene and other organic compounds degrading bacteria like Comamonas. ${ }^{37}$ The Flavobacterium and Leadbetterella also similar increased in R2 reactor contrast to R1 with the operation time, which have been guessed that their growth has an advantage under the addition of tetracycline and they might take part in tetracycline degradation.
The Luteolibacter increased significantly in R1 reactor with the increase of operation time. The abundances of the Luteolibacter in R1 reactor were 3.96\%, 4.7\%, 12.24\%, 21.78\%, 24.34\% and $11.62 \%$ respectively along with the increasing operation time, indicating that the Luteolibacter could adapt the operational conditions of the AGSBR technology. However, the Luteolibacter appeared the decreasing trend in R2 reactor with relative abundance decreasing from $5.92 \%$ in $2-1$ to $2.76 \%$ in R2-6. The experiment proved that the tetracycline has a significant influence on the Luteolibacter. The Thauera has the highest abundances $25.79 \%$ and $23.51 \%$ in R1-1 and R2-1 respectively, and was predominant in the SBR system. While the Thauera dropped gradually with the increasing operation time, even the abundances of Thauera decreased to $4.97 \%$ and $7.69 \%$ in R1-6 and R2-6 respectively, which could conclude that the Thauera was dramatically affected by operational conditions of the AGSBR technology. It indicated that tetracycline drugs had little effect on the Thauera. With its wide organic matter degradation ability, ${ }^{38-42}$ the effective removal of COD at the beginning of the operation of reactors was closely related to it. Similar microorganisms include Zoogloea, and unclassified microbes, they also changed obviously after 30 days.

Based on the above experiment results, the existence of some resistant tetracycline bacterias made AGS adapt to live and thrive in the addition of tetracycline. Moreover, the tetracycline could stimulate bacteria produce more extracellular polymeric substances to protect itself from adverse environment. With the addition of tetracycline, an AGS system dominated by tetracycline degradation genera was gradually formed with increasing relative abundance of Chryseobacterium, Actinotignum, Lactococcus, Shinella, and 


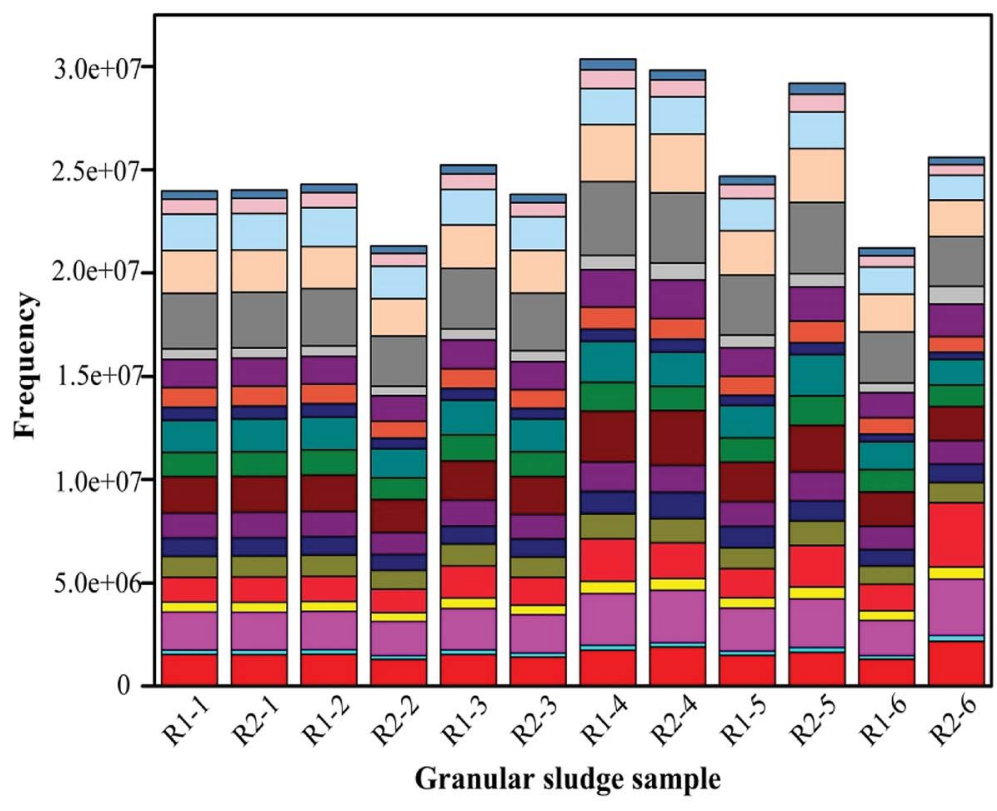

Z Cytoskeleton

W Extracellular structures

V Defense mechanisms

U Intracellular trafficking, secretion, and vesicular transport

T Signal transduction mechanisms

F Function unknown

$\mathrm{R}$ General function prediction only

Q Secondary metabolites biosynthesis, transport, and catabolism

$\mathrm{P}$ Inorganic ion transport and metabolism

o Post-translational modification, protein turnover, and chaperones

N Cell motility

M Cell wall/membrane/envelope biogenesis

L Replication, recombination and repair

KTranscription

J Translation, ribosomal structure and biogenesis

Lipid transport and metabolism

H Coenzyme transport and metabolism

G Carbohydrate transport and metabolism

F Nucleotide transport and metabolism

E Amino acid transport and metabolism

D Cell cycle control, cell division, chromosome partitioning

C Energy production and conversion

B Chromatin structure and dynamics

A RNA processing and modification

Fig. 7 The distribution of functional genes in two reactors during different phases.

Clavibacter. Besides, the Comamonas, Flavobacterium and Leadbetterella were showed a remarkable versatility with respect to their tetracycline resistance. The changing microbial populations during degradation of pollutants may result from cooperative or synergistic effects where the presence of one microbial population promotes growth of other specific types. The interaction between different bacterial populations may play an important role in the degradation of organic matter and on the stability of the system.

\section{The analysis of functional bacterial genes in AGS}

The high-throughput sequencing technique was also used to detect the change of functional genes in AGS. COG-based functional structure distribution diagram as shown in Fig. 7 . The functional genes in R1-1 and R2-1 were similar. Compared with the R1-2, the abundances of functional genes decreased in R2-2, especially for C, E, G, P, and Q. The genes had the roles in amino acid and carbohydrate transport and metabolism, they also affected in energy production and conversion, and secondary metabolites biosynthesis, inorganic ion transport and metabolism. The action mechanism of tetracycline on microorganism is to prevent the connection of amino acid-tRNA on the bit by combining with the A position of ribosome $30 \mathrm{~S}$ within the bacterial cells to inhibit the growth of the peptide chain and affect the synthesis of bacterial proteins further. ${ }^{43}$ Thus, at the initial stage of the operation, tetracycline had an obvious inhibiting effect on microorganisms, which made its removal rate low. At this phase, the effluent concentration of tetracycline did not decrease significantly, and the removal rate was only approximately $74 \%$, which was partly related with the decreasing number of functional genes.
Compared with that in R1-3, the number of functional genes in R2-3 gradually restored. The change law of functional genes in R2-4 and R1-4 was similar to that in the previous phase, in which the $\mathrm{E}$ and $\mathrm{G}$ were improved considerably. The function genes $\mathrm{E}$ and $\mathrm{G}$ in the AGSBR system had a great effect on the degradation of tetracycline. The removal rate of tetracycline increased at this phase (Fig. 4). The functional genes $\mathrm{C}, \mathrm{P}$ and $\mathrm{Q}$ in R2-6 contrast to R1-6 increased, and the study indicated that the increase of those functional genes could promote the degradation of antibiotic..$^{44}$

\section{Microbial population dynamics}

Fig. 8 showed the Venn diagram of the samples in two reactors at different phases. It can be seen from Fig. 8a that 2262 OTUS were shared among the sludge samples form R1-6 and R2-6, representing about $52.0 \%$ and $55.5 \%$ of the total sequences, respectively. The variation of microbial structure happened along with adding tetracycline drug. Fig. 8b further illustrated the microbiome succession of samples from the $\mathrm{R} 1$ and $\mathrm{R} 2$ reactors during different operational phases. In each phase, there were unique OTUs and they represented from $39.1 \%$ to $80.3 \%$ of the total sequences. 92 OTUs were shared among the sludge samples. This core microbiome, consisting of OTUs detected over the whole samples, was found to include members belonging to Proteobacteria, Firmicutes, Actinobacteria and Bacteroidetes. Some bacterias adapting to tetracycline grew well and gradually predominated in the AGSBR system, while others without tetracycline-resistance capacity were gradually weakened or died out with operating time. Besides, the prosperity of some adapting tetracycline bacterias changed the diversity and richness of microbial community. 


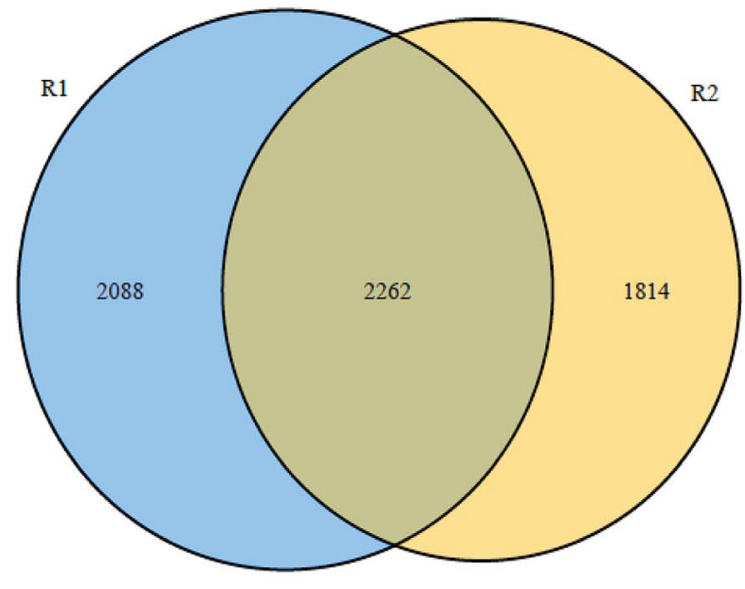

(a)

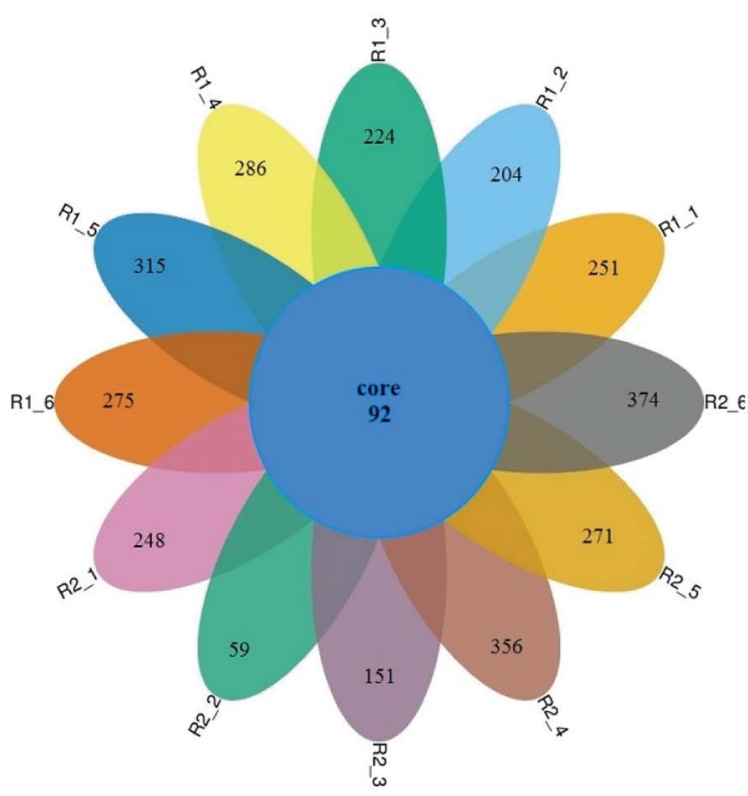

(b)

Fig. 8 The Venn diagram of samples from two reactors. (a) The blue represented R1-6 and the orange represented R2-6, and the overlapping phylotype together represented the shared OTU; (b) different color represented samples from two reactors during different phases.

\section{Conclusions}

This study describes a biological technique for tetracycline removal from livestock and poultry wastewater using an AGS in SBR. Initially, tetracycline addition negatively affected granular quality, but after microbial adaptation, the system recovered and effectively removed tetracycline. The removal rate of tetracycline was more than $90 \%$, and the removal rates of COD, $\mathrm{NH}_{4}{ }^{+}-\mathrm{N}$ and TP were more than $95 \%$, 85\% and $90 \%$, respectively. By comparison with some existing methods, ${ }^{16,17,45,46}$ the proposed method has advantages of high removal efficiency for tetracycline, $\mathrm{COD}, \mathrm{NH}_{4}{ }^{+}-\mathrm{N}$ and TP. The tetracycline removal was dependent on the adsorption and biodegradation of AGS, and the biodegradation played a dominant role. The high-throughput sequencing with microbial taxonomic profiling analyses showed tetracycline dosing promoted dominance of Chryseobacterium, Actinotignum, Lactococcus, Shinella, and Clavibacter at the genus level. The increase of functional genes such as amino acid, carbohydrate and inorganic ion transport and metabolism, played an important role in the degradation of tetracycline. The bacterial community of granules was dynamic but a pronounced shift in its structure occurred during tetracycline feeding. Nevertheless, a core microbiome was maintained.

\section{Conflicts of interest}

All authors declare that they have no conflict of interest.

\section{Acknowledgements}

The work was supported by the National Natural Science Foundation of China (21667017 and 51608148), the State Key Laboratory of Urban Water Resource and Environment, Harbin Institute of Technology (2017TS02).

\section{References}

1 X. Lu, J. Luo, Y. Gao, S. Yan and Z. Zhang, Jiangsu Journal of Agricultural Sciences, 2014, 671-681.

2 Y. Miao, Z. Shen, Y. Zhou and S. Liu, Res. J. Environ. Sci., 2016, 29, 1075-1082.

3 L. Wan, Y. Zou, X. Gong and J. Wan, Res. J. Environ. Sci., 2015, 28, 1302-1310.

4 J. Han, R. Wu, H. Jing and C. Yansong, Technol. Water Treat., 2008, 34, 7-11.

5 L. Wang, C. Chen, Y. Chen and W. Wu, Environmental Science, 2013, 34, 979-985.

6 Y. Zhuang, Y. Gao, Y. Deng, X. Zhang and C. Geng, Environ. Chem., 2015, 1356-1362.

7 J. Wang, W. Ben, M. Yang, Y. Zhang and Z. Qiang, Environ. Int., 2016, 92-93, 317-323.

8 Y. Chen, H. Zhang, Y. Luo and J. Song, Environ. Monit. Assess., 2012, 184, 2205-2217.

9 W. Ben, Z. Qiang, C. Adams, H. Zhang and L. Chen, J. Chromatogr. A, 2008, 1202, 173-180.

10 X. P. Z. Q. Chen, J. Environ. Sci., 2011, 23, 1729-1737.

11 J. Chen, Y. Liu, J. Zhang, Y. Yang, L. Hu, Y. Yang, J. Zhao, F. Chen and G. Ying, Bioresour. Technol., 2017, 238, 70-77. 
12 B. Wilson and F. B. Pyatt, Bull. Environ. Contam. Toxicol., 2007, 78, 390-394.

13 Q. Zhou, Y. Luo and M. Wang, Asian Journal of Ecotoxicology, 2007, 2, 243-251.

14 F. Pomati, A. Netting, D. Calamari and B. Neilan, Aquat. Toxicol., 2004, 67, 387-396.

15 A. B. Boxall, L. A. Fogg, P. A. Blackwell, P. Kay, E. J. Pemberton and A. Croxford, Rev. Environ. Contam. Toxicol., 2004, 180, 1-91.

16 K. Košutić, D. Dolar, D. Ašperger and B. Kunst, Sep. Purif. Technol., 2007, 53, 244-249.

$17 \mathrm{X}$. Cheng, Study on preparation and properties of high-flux, anti-fouling nanofiltration membranes and their application in separation of antibiotics, Harbin Institute of Technology, 2016.

18 L. Jiang, L. Xie, Q. Zhou and D. Ying, China Water \& Wastewater, 2010, 18-22.

19 J. Fang, Experimental investigations of anaerobic aminate and producing gas rate by UASB disposing breed aquatics wastewater, Southwest Jiaotong University, 2008.

20 A. Tremouli, G. Antonopoulou, S. Bebelis and G. Lyberatos, Bioresour. Technol., 2013, 131, 380-389.

21 SEPA, The Editorial Committee of Water and Wastewater Monitoring and Analysis Methods, Water and Wastewater Monitoring and Analysis Methods, China Environmental Science Press, Beijing, China, 4th edn, 2002.

22 Y. J. Shi, X. H. Wang, Z. Qi, M. H. Diao and M. M. Gao, J. Hazard. Mater., 2011, 191, 103-109.

23 K. M. Kerr, R. J. Larson and D. C. Mcavoy, Ecotoxicol. Environ. Saf., 2000, 47, 314-322.

24 E. Cetin, E. Karakas, E. Dulekgurgen, S. Ovez, M. Kolukirik and G. Yilmaz, Water Res., 2018, 131, 74-89.

25 R. C. Edgar, B. J. Haas, J. C. Clemente, C. Quince and R. Knight, Bioinformatics, 2011, 27, 2194-2200.

$26 \mathrm{H}$. Shenglin, Effect of tetracycline antibiotic on the corresponding resistance of degrading bacteria and community structure in an activated sludge system, Donghua University, 2015.

27 X. Zhao, Y. Zhao, Z. Chen, F. Jiang, H. Luo and H. Feng, China Water \& Wastewater, 2012, 28, 15-19.
28 X. XiangRong and L. XiaoYan, Chemosphere, 2010, 430-436.

29 H. Beilin and L. Ke, Jiangsu Academy of Agricultural Sciences, 2013, 41, 345-347.

30 L. Ji, W. Chen, L. Duan and D. Zhu, Environ. Sci. Technol., 2009, 7, 2322-2327.

31 R. Rostamian and H. Behnejad, Ecotoxicol. Environ. Saf., 2018, 147, 117-123.

32 S. Bellais, L. Poirel, S. Leotard, T. Naas and P. Nordmann, Antimicrob. Agents Chemother., 2000, 44, 3028-3034.

33 S. Bellais, D. Aubert, T. Naas and P. Nordmann, Antimicrob. Agents Chemother., 2000, 44, 1878-1886.

34 B. A. Sullivan, T. Gentry and R. Karthikeyan, J. Appl. Microbiol., 2013, 115, 774-785.

35 S. Maraki, G. Evangelou, D. Stafylaki and E. Scoulica, Anaerobe, 2017, 43, 43-46.

36 S. Bank, A. Jensen, T. M. Hansen, K. M. Søby and J. Prag, Emerging Infect. Dis., 2010, 16, 76-80.

37 L. Yichen, C. Juan, G. Guoqing and S. Biao, Res. J. Environ. Sci., 2008, 21, 27-31.

38 W. M. Chen, Y. S. Lin, C. C. Young and S. Y. Sheu, Int. J. Syst. Evol. Microbiol., 2013, 63, 169-174.

39 A. Tschech and G. Fuchs, Arch. Microbiol., 1987, 148, 213217.

40 S. H. Baek and J. P. Shapleigh, Appl. Environ. Microbiol., 2005, 71, 4427-4436.

41 Y. Shinoda, Y. Sakai, H. Uenishi, Y. Uchihashi, A. Hiraishi, H. Yukawa, H. Yurimoto and N. Kato, Appl. Environ. Microbiol., 2004, 70, 1385-1392.

42 J. M. Macy, G. Rech, M. Auling, E. Dorsch, L. I. Stackebrandt and S. Sly, Int. J. Syst. Bacteriol., 1993, 43, 135-142.

43 L. Juanying, W. Xiaoying, X. Manjun, L. Yun and L. Yongyan, Chin. J. Environ. Eng., 2014, 8, 573-580.

44 L. Qinan, Degradation and transformation mechanism of residual veterinary drugs during advanced oxidation process in aqueous matrices, Hefei University of Technology, 2016.

45 N. Morales, M. Figueroa, A. Fra-Vázquez, A. Río and J. L. Campos, Process Biochem., 2013, 1216-1221.

46 Y. Zhao, J. Huang, H. Zhao and H. Yang, Bioresour. Technol., 2013, 143, 439-446. 